\title{
Beyond Memory, Navigation, and Inhibition: Behavioral Evidence for Hippocampus-Dependent Cognitive Coordination in the Rat
}

\author{
Malgorzata Wesierska, ${ }^{1}$ Colleen Dockery, ${ }^{2}$ and André A. Fenton ${ }^{2,3}$ \\ ${ }^{1}$ Nencki Institute of Experimental Biology, 02-093 Warsaw, Poland, ${ }^{2}$ Institute of Physiology, Academy of Sciences of the Czech Republic, 14220 Prague, \\ Czech Republic, and ${ }^{3}$ Department of Physiology and Pharmacology, State University of New York, Downstate Medical Center, Brooklyn, New York 11203
}

\begin{abstract}
Injecting tetrodotoxin (TTX) into one hippocampus impaired avoidance of a place defined by distal cues while rats were on a slowly rotating arena. The impairment could be explained by a deficit in memory, navigation, or behavioral inhibition. Here, we show that the TTX injection abolished the ability of rats to organize place-avoidance behavior specifically when distal room and local arena cues were continuously dissociated. The results provide evidence that injecting TTX into one hippocampus specifically impaired the coordination of representations that support organized behavior because of the following: (1) rats normally coordinate separate room and arena avoidance memories; (2) the TTX injection spared spatial, relational, and representational memory, navigation, and behavioral inhibition; and (3) the TTX-induced impairment of place avoidance depended on the need to coordinate representations of local and distal stimuli.
\end{abstract}

Key words: cognitive coordination; cognitive disorganization; spatial cognition; reversible lesion; dynamic grouping; hippocampus

\section{Introduction}

We developed a place-avoidance task to study rapidly acquired spatial cognition in a dry environment without food or water deprivation (Cimadevilla et al., 2000b). Rats on a rotating arena were conditioned to avoid a stationary part of the room. The rotation continuously dissociated room and arena stimuli. The rats were challenged to selectively ignore the rotating stimuli, which were irrelevant for avoidance. Injecting tetrodotoxin (TTX) into both hippocampi confirmed the task was hippocampus dependent (Cimadevilla et al., 2000a). Unilateral hippocampal dysfunction spared learning in other spatial tasks (Olton et al., 1982; Sutherland et al., 1983; Fenton and Bureš, 1993; Fenton et al., 1995; Moser and Moser, 1998), and we wanted to confirm this for place avoidance as a basis for studying how information is organized between the hippocampi. Injecting TTX into one dorsal hippocampus unexpectedly abolished learning, consolidation, and retrieval of place avoidance on the rotating arena (Cimadevilla et al., 2001).

Three well-supported hypotheses account for the unilateral

\footnotetext{
Received Sept. 24, 2004; revised Jan. 22, 2005; accepted Jan. 22, 2005.

This work was supported by the Fifth Framework Research and Technological Development Program of the European Commission (QLG3-CT-1999-00192) in the framework of Academy of Sciences of the Czech Republic Grant AV0Z 5011922. M.W. was supported by a statutory grant from the State Committee for Scientific Research (Poland) to the Nencki Institute. We thank Jan Svoboda for help with training. Bill Phillips and Steve Silverstein provided valuable comments and discussion. The encouraging criticisms of two anonymous reviewers substantially improved this manuscript.

Correspondence should be addressed to André Fenton, Department of Physiology and Pharmacology, State University of New York, Downstate Medical Center, 450 Clarkson Avenue, Brooklyn, NY 11203. E-mail: afenton@downstate.edu.

DOI:10.1523/JNEUROSCI.3962-04.2005

Copyright $\odot 2005$ Society for Neuroscience $\quad$ 0270-6474/05/252413-07\$15.00/0
}

TTX-induced deficits. The injection may have impaired spatial or relational memory (Eichenbaum et al., 1999), navigation (O'Keefe and Nadel, 1978), or behavioral inhibition, the ability to inhibit inappropriate responses (Jarrard, 1973; McNaughton, 1997; Chan et al., 2001; Tracy et al., 2001).

Rats coordinated separate place-avoidance representations of dissociated room and rotating stimuli (Bureš et al., 1997; Fenton et al., 1998), providing a fourth explanation for the TTX-induced deficit. The injection may have impaired coordinating the representations that underlie room- and arena-specific avoidance. The concept of cognitive coordination is rooted in neurophysiology and neuroanatomy (Phillips and Singer, 1997), was formalized in information theory (Phillips et al., 1995; Kay et al., 1998), and was used to develop measures of the modulatory role of attention (Phillips and Craven, 2000). Cognitive coordination was defined as the family of interactions that modify neuronal dynamics without changing receptive fields (Phillips and Singer, 1997; Phillips and Silverstein, 2003). Cognitive coordination is inferred from human behavior when contextual modulation and perceptual grouping of stimuli control responses. Contextual modulation is illustrated when the symbol $\mid 3$ is interpreted either as the letter B or the number 13 if it is presented in the context of letters $(\mathrm{A} \mid 3 \mathrm{C})$ or numerals $(|2| 3 \mid 4)$ (Phillips and Silverstein, 2003). Perceptual grouping explains why it is harder to perceive the number in the presence of letters (and vice versa). The operational criteria for inferring cognitive coordination from rat behavior were as follows: criterion 1 ( $\mathrm{cc} 1$ ), in the presence of multiple stimulus sets that can be segregated, cognitive behavior is organized according to the behaviorally relevant stimulus subset according to the demands of the current context; criterion 2 (cc2), the cognitive behavior is expressed during steady-state physical conditions in 
which there is potential for interference from concurrent cognitive processes (we set operational criteria for inferring impaired cognitive coordination or as it is called cognitive disorganization); criterion 1 (cd1), disorganized cognitive responses during steady state, physical conditions in which baseline responses of healthy or untreated subjects satisfy criteria for cognitive coordination; criterion $2(\mathrm{~cd} 2)$, intact cognitive responses when cognitive coordination is unnecessary. These experiments determined whether deficits of memory, navigation, behavioral inhibition, or cognitive coordination could explain the TTX-induced impairment.

\section{Materials and Methods}

All procedures have been described previously (Fenton et al., 1998; Cimadevilla et al., 2000a, 2001) and were in accordance with institutional and National Institutes of Health guidelines. The rats were trained to search the arena for scattered food and thus approach the vicinity of the to-be-avoided place (Fig. 1) (Bureš et al., 1997; Fenton et al., 1998). The to-be-avoided place could be defined by "room" cues, which were distal visual cues that were always fixed in the room. "Arena" cues that were fixed on the arena surface could also define the to-beavoided place. These were mostly olfactory stimuli (feces, urine, scent marks) that were deposited during a session. Place avoidance was studied in four conditions that manipulated the presence of room and arena stimuli, their mutual dissociation, and whether their use was reinforced by avoidance conditioning. The conditions are named to indicate the presence of the room-fixed and arenafixed conditioned stimuli. The "+" and "-" symbols signify whether or not the stimulus set defined the to-be-avoided place.

It is useful to consider these conditions by analogy to a carousel in a park. Localizing oneself can be accomplished by referencing landmarks in the park, which are analogous to room cues. One can also localize oneself by referencing the mechanical horses on the carousel, analogous to using arena cues. There is a specific challenge to selectively use either park landmarks or the horses to localize oneself when the carousel rotates.

In the "(Room\&Arena)+" task (Fig. 1C), the room was illuminated, and the arena was stable, and thus room and arena stimuli could be represented as a single configuration and room locations mapped to a single arena location. The rat was therefore conditioned to avoid a place defined by both sets of cues. In the "Arena+" task (Fig. 1D), the arena rotated in darkness, and in the absence of room cues, the rats were conditioned to avoid a place defined by the rotating arena cues. In the "Room+" task (Fig. 1 E), the room was illuminated, the arena cues were hidden by shallow water, and the rats were reinforced to avoid a place defined by the room cues while the arena rotated. In the "Room+Arena-"task (Fig. 1 F) (Cimadevilla et al., 2001), the to-beavoided place was defined by the room cues but not by the cues on the rotating dry arena. We did not control for the ability of the rat to perform path integration, but we did control whether the cumulative error in path integration relative to the to-be-avoided place could be corrected by room or arena cues.

Forty-two adult male Long-Evans rats from the Institute of Physiology breeding colony were used. The rats were food deprived to $85 \%$ of their free-feeding weights $(280-300 \mathrm{~g})$ and then trained for 1 week to forage for scattered food on the stable $82-\mathrm{cm}$-diameter elevated $(75 \mathrm{~cm})$ arena.
The arena (Bio-Signal Group, Brooklyn, NY) was made from conductive aluminum and had a $5 \mathrm{~cm}$ lip to hold water. A computer-controlled electromotor could rotate the arena at $1 \mathrm{rpm}$. After 1 week of foraging, the rats were anesthetized by Nembutal $(50 \mathrm{mg} / \mathrm{kg}$, i.p.) and then surgically implanted with a pair of guide cannulas aimed at the dorsal hippocampi (relative to bregma: posterior, 3.5 ; lateral, \pm 2.6 ; ventral, 2.0). A low-impedance, $\mathrm{U}$-shaped shock electrode made from a 25 gauge hypodermic needle was implanted by piercing the skin on the back between the shoulders and soldering a screw to the sharp end. The screw prevented the needle from slipping out and provided purchase for an alligator clip, which could be connected to the electrode for delivering shock. One week after surgery, the foraging training was resumed for $3 \mathrm{~d}$.

Intrahippocampal injections of saline or $5 \mathrm{ng}$ of TTX dissolved in $1 \mu \mathrm{l}$ of saline were made through one guide cannula during $1 \mathrm{~min}$ (Zhuravin and Bureš, 1991; Fenton and Bureš, 1993; Fenton et al., 1995; Cimadevilla et al., 2001). A habituating TTX injection was given 1 week after surgery, and the rats were observed for signs of ataxia, but none were observed, suggesting proper cannula placement, which was confirmed histologically after testing (Fig. 1G,H). All other injections were given $1 \mathrm{~h}$ before training. Unoperated rats (intact) served as controls for group comparisons. Saline-injected controls were used in the previous study of Room + Arena - avoidance (Cimadevilla et al., 2001), which was the only task that was impaired by the TTX injection in the current study. Injected rats were always injected in the same hippocampus. One-half of the animals were injected in the left side, and the other half were injected in the right side.

A commercial place-avoidance system was used to collect and analyze the data (Bio-Signal Group). The rat wore a latex harness that held infrared light-emitting diodes between its shoulders. The diodes were powered via two conductors of a three-conductor cable. The third conductor 
carried the shock current. It was connected to the screw on the shock electrode by a mini alligator clip. A rat was placed on the arena, and food pellets were dropped into the arena from an overhead feeder that was triggered every $20 \mathrm{~s}$ by the tracking system (iTrack; Bio-Signal Group). Pasta pellets $(20 \mathrm{mg})$ were used when the arena was dry, and Cocoa Puffs (General Mills, Minneapolis, MN) were used when the arena was wet, because they floated and remained intact during the session. Whenever the rat entered the $60^{\circ}$ to-be-avoided sector, a computer-triggered, constant-current $(50 \mathrm{~Hz}, 0.5 \mathrm{~s})$ shock was delivered across the lowimpedance $(\sim 100 \Omega)$ electrode and the high-impedance $(\sim 100 \mathrm{k} \Omega)$ electrode of the rat's contact to the grounded arena surface. During the first session for each rat, the shock current was adjusted to the minimum value $(0.2-0.5 \mathrm{~mA})$ that would elicit flinch and escape responses. If the rat did not leave the to-be-avoided place within $1.5 \mathrm{~s}$, it was shocked again. Sessions lasted $20 \mathrm{~min}$. Place avoidance was measured by the number of entrances to the to-be-avoided place (E), and the maximum time without entering the to-be-avoided place $\left(\mathrm{T}_{\max }\right)$. The straightness of the rats' path seemed to depend on the version of the place-avoidance task and whether or not they had been injected with TTX. Thus we calculated the "linearity" (Lin) of the path as the average ratio of the distance between a rat's position at $2 \mathrm{~s}$ intervals and the distance during the $2 \mathrm{~s}$ determined by integrating the distances between the rat's position every 20 ms. Two-way repeated-measures ANOVAs and Newman-Keuls post hoc tests were used for comparisons between groups and across days. Within-subject comparisons were made by a one-way, repeatedmeasures ANOVA. Statistical significance was accepted for $p<0.05$. Averages \pm SEM are reported.

If the TTX-induced hippocampal dysfunction was sufficient to impair behavior, the memory, navigational, behavioral inhibition, and cognitive coordination hypotheses predict different outcomes for the experiments that are outlined below.

Experiment 1a: does TTX injection impair (RoomeArena)+ place avoidance? Rats were pretrained to forage throughout the arena for scattered food. The room and arena cues were not dissociated. The performance of 12 TTX-injected and 12 unoperated control rats was compared for $4 \mathrm{~d}$. This training was shown previously to cause rats to form autonomous room frame and arena frame place-avoidance memories (Bureš et al., 1997; Fenton et al., 1998). The memory and navigation hypotheses predict an impairment if the memory and navigational demands are sufficiently strong. The behavioral inhibition hypothesis predicts a TTXinduced impairment, because the rats are required to inhibit foraging for food in the to-be-avoided area. The cognitive coordination hypothesis predicts no impairment, because contextual modulation or perceptual grouping of room and arena cues is unnecessary.

Experiment 1b: does TTX injection impair Arena+ place avoidance? Room and arena cues were not dissociated, because room cues were hidden by darkness. The arena rotated, and the to-be-avoided area was defined by arena cues. One-half of the rats from each of the experiment 1a groups were trained in Arena + avoidance for $3 \mathrm{~d}$. The memory and navigation hypotheses predict impairments as long as the memory and navigational demands are sufficient. The behavioral inhibition hypothesis predicts an impairment, because the rat must inhibit foraging in a part of the arena. The cognitive coordination hypothesis does not predict an impairment, because contextual modulation or perceptual grouping of room and arena cues is not required.

Experiment 1c: does TTX injection impair Room + Arena- place avoidance? The room was illuminated, and the arena rotated to dissociate room and arena cues. The to-be-avoided place was defined by room cues. The other half of the rats from experiment la were trained in Room + Arena - avoidance for $3 \mathrm{~d}$. The memory and navigational hypotheses predict an impairment if memory and navigational demands are sufficient. The behavioral inhibition hypothesis predicts less of an impairment than in the (Room\&Arena) + and Arena + tasks, because foraging for food should only be inhibited when the food is in the roomdefined to-be-avoided place, and this is only one-sixth of the time. The cognitive coordination hypothesis predicts an impairment, because contextual modulation and perceptual grouping (and segregation) are required to selectively associate shock with room locations.

Experiment 2: does shallow water remove salient arena stimuli? A pre- requisite for testing the effect of the TTX injection on Room + avoidance is that arena cues can be hidden. This experiment tested whether shallow water hid arena cues enough to impair arena cue-based place avoidance. The arena was filled with water $(1 \mathrm{~cm}$ deep) and rotated. The to-beavoided sector was defined with respect to the rotating arena. Nine naive rats were trained in darkness to avoid an arena-defined sector for $6 \mathrm{~d}$. If the water reduced the salience of arena cues, only temporal or selfmovement path integration cues could have been used to identify the to-be-avoided sector. Path integration can only support place avoidance for $\sim 2 \mathrm{~min}$ (Stuchlik et al., 2001), and thus performance was expected to be poor.

Experiment 3a: does rotating the arena affect Room + avoidance? Nine naive rats were implanted with injection cannulas and trained in Room + avoidance for $6 \mathrm{~d}$ on the stable wet arena. To determine whether place avoidance differed when the wet arena was stable or rotating, the arena was stable for $20 \mathrm{~min}$ and then rotated for $20 \mathrm{~min}$ on each of $4 \mathrm{~d}$.

Experiment 3b: does TTX injection impair Room + place avoidance? The rats from experiment $3 \mathrm{a}$ were used to test whether the TTX injection impaired Room + place avoidance on the rotating arena. By day 11, the rats had been performing optimally for several days. They were all injected with saline and trained to establish a baseline for Room + avoidance. On days 12-14, the rats were injected with TTX in one hippocampus and then trained in the same Room + task. Performance on days 11-14 was compared to determine whether TTX impaired Room + avoidance. The memory and navigational hypotheses predict an impairment if memory and navigational demands are sufficient. The behavioral inhibition hypothesis predicts a mild impairment as in the Room + Arena - task, because foraging only has to be inhibited one-sixth of the time. The cognitive coordination hypothesis does not predict an impairment, because contextual modulation of room and arena stimuli is not necessary.

\section{Results}

\section{Experiment 1a: does the TTX injection impair}

\section{(Room\&Arena) + avoidance?}

Both groups of rats learned the place-avoidance task rapidly (Fig. $2 A)$. The number of entrances decreased across days $\left(\mathrm{E}: F_{(3,66)}=\right.$ $5.4, p<0.002$, day $1>$ day $2=$ day $3 ; T_{\max }: F_{(3,66)}=0.84, p>$ $0.48)$. The groups did not differ $\left(\mathrm{E}: F_{(1,22)}=0.003, p>0.96 ; T_{\max }\right.$ : $\left.F_{(1,22)}=0.48, p>0.49\right)$, and there was no interaction $\left(\mathrm{E}: F_{(3,66)}=\right.$ $\left.1.01, p>0.40 ; T_{\max }: F_{(3,66)}=1.07, p>0.37\right)$. Although the TTX-injected rats walked a distance similar to that seen for the controls (data not shown), their paths were less linear (Fig. 2A) $\left(F_{(1,22)}=4.3 ; p<0.05\right)$. This did not change over days $\left(F_{(3,66)}=\right.$ $1.18 ; p>0.32)$, and the group by day interaction was not significant $\left(F_{(3,66)}=0.13 ; p>0.94\right)$. This training establishes autonomous memories for avoiding the overlapping room and arena to-be-avoided places (Bureš et al., 1997; Fenton et al., 1998) that the rats could use in the next phase when the room and arena cues were dissociated.

\section{Experiment 1b: does the TTX injection impair Arena+ avoidance?}

Because there was no conflict with the room and arena memories that were established by the previous (Room\&Arena) + training, both the intact and TTX-injected rats performed the Arena + task well from the first session (Fig. $2 B$ ). The number of entrances differed across days $\left(\mathrm{E}: F_{(2,20)}=4.64, p<0.02\right.$, day $1>$ day $2=$ day 3; $\left.T_{\max }: F_{(2,20)}=3.29, p>0.06\right)$. Overall, the groups were not different $\left(\mathrm{E}: F_{(1,10)}=0.53, p<0.48 ; T_{\text {max }}: F_{(1,10)}=0.57, p>\right.$ 0.47 ), but the TTX-injected animals were slightly better on day 2 , resulting in a significant group by day interaction in the maximum time-avoided measure $\left(\mathrm{E}: F_{(2,20)}=3.31, p>0.06 ; T_{\max }\right.$ : $F_{(2,20)}=7.98, p<0.003$; intact: day $1=$ day $3<$ day 2 ; intact day $2=$ TTX: day $1=$ day $2=$ day 3$)$. The linearity of the path was relatively low in both groups (Fig. $2 B$ ) and did not differ between 
A
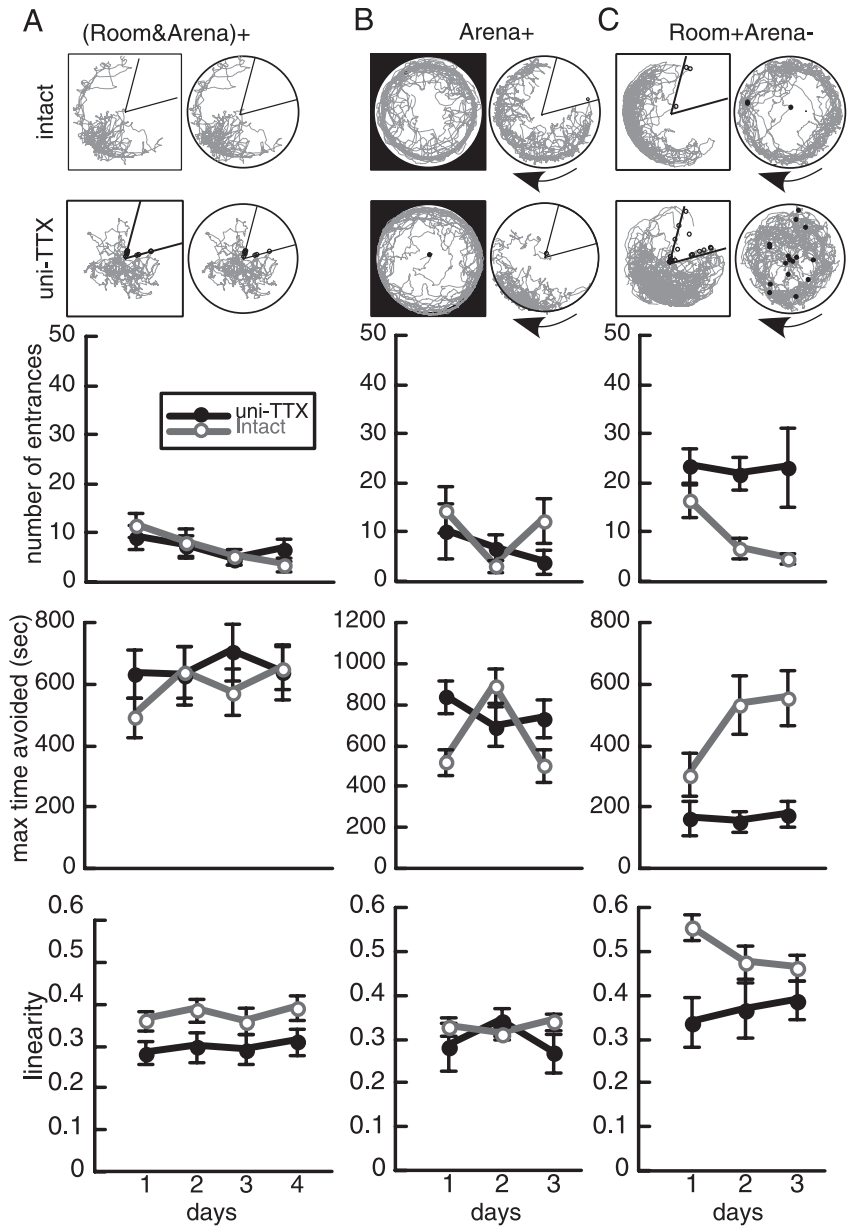

Figure 2. Injecting TTX into one hippocampus (uni-TTX) did not impair (Room\&Arena) + place avoidance $(\boldsymbol{A})$ or Arena + place avoidance $(\boldsymbol{B})$ but abolished Room + Arena - place avoidance $(\boldsymbol{C})$. Three measures are plotted. Avoidance is indicated by a low number of entrances to the to-be-avoided place and a high maximum time of avoidance. Linearity does not measure avoidance; it describes how straight a rat's path was in the arena. A major difference in avoidance between the two groups is observed only in the Room + Arena - task. The separate room (left) and arena (right) frame tracks of a representative rat in each group are shown above the plots for the final session of each condition. The room frame in light and darkness is represented by a white or black square, respectively. The arena frame is represented by a circle, and rotation is represented by the curved arrow. The limits of the to-be-avoided sector are indicated by black lines, and shocks delivered there are indicated by small unfilled circles. The locations of those shocks in the other frame are marked by small filled circles.

the groups $\left(F_{(1,10)}=0.58 ; p>0.46\right)$ or across days $\left(F_{(2,20)}=0.57\right.$; $p>0.58)$, and thus there was also no interaction $\left(F_{(2,20)}=2.40\right.$; $p>0.11)$.

\section{Experiment 1c: does the TTX injection impair}

Room + Arena - avoidance?

The groups were different $\left(\mathrm{E}: F_{(1,10)}=12.34, p<0.006\right.$; $T_{\max }$ : $\left.F_{(1,10)}=18.54, p<0.002\right)$. The intact rats learned the Room + Arena - task rapidly, but the TTX-injected rats did not improve across $3 \mathrm{~d}$ (Fig. 2C), replicating the previous result (Cimadevilla et al., 2001). The effects of day $\left(\mathrm{E}: F_{(2,20)}=2.13\right.$, $\left.p>0.14 ; T_{\max }: F_{(2,20)}=4.80, p<0.02\right)$ and interaction $\left(\mathrm{E}: F_{(2,20)}=1.62, p>0.22 ; T_{\max }: F_{(2,20)}=4.55, p<0.02\right.$; intact day $1=$ day $2=$ day $3>$ TTX day $2=$ day 3$)$ were only significant on the maximum time-avoided measure. The TTX rats had less linear paths than the controls $\left(F_{(1,10)}=5.47 ; p<0.04\right)$. Although the effect of day on linearity was not significant $\left(F_{(2,20)}=0.68\right.$; $p>0.52)$, the group by day interaction was significant $\left(F_{(2,20)}=\right.$
4.86; $p<0.02$ ), because linearity decreased in the controls across days ( $p$ values $<0.05$ ), and there was a nonsignificant trend for linearity to increase in the TTX-injected rats.

The TTX-injected rats had less well organized escapes from the to-be-avoided place. They often moved deeper into the to-beavoided sector and were shocked repeatedly. On the third day, the controls received on average $1.7 \pm 0.26$ shocks each time they entered the to be-avoided place. The TTX-injected rats received $4.1 \pm$ 1.4 shocks per entrance $\left(t_{10}=2.2\right.$; one-tailed $t$ test, $\left.p=0.05\right)$.

\section{Experiment 2: does shallow water remove salient} arena stimuli?

Arena + avoidance was poor in the wet arena (Fig. $3 A$ ) in contrast to the dry arena (Fig. $2 B$ ). The rats entered the to-be-avoided sector $\sim 20$ times per session and did not improve across the $6 \mathrm{~d}$. In fact, the number of entrances increased $\left(F_{(5,40)}=2.59 ; p<\right.$ 0.04 ; day $6>$ day 3 ). The ability to avoid, on the basis of path integration alone, was limited. On average, the rats did not avoid entering the to-be-avoided place if they walked for $69.8 \pm 17.8 \mathrm{~s}$ or $2.40 \pm 0.47 \mathrm{~m}$. The maximum time avoided was $>300 \mathrm{~s}$ and did not change across days $\left(F_{(5,40)}=0.73 ; p>0.60\right)$. The linearity of the path was low and changed across days $\left(F_{(5,40)}=4.41 ; p>\right.$ $0.003)$. It started at 0.19 and decreased to $\sim 0.15$ on days $2-5$ before returning to 0.19 on day 6 , suggesting that the rats walked in a tortuous manner in an effort to avoid shock.

\section{Experiment 3a: does rotating the arena affect}

\section{Room + avoidance?}

Place avoidance was asymptotic across the $4 \mathrm{~d}$ but better when the arena was stable (Fig. $3 B)\left(\mathrm{E}: F_{(1,16)}=12.4, p<0.003 ; T_{\max }\right.$ : $\left.F_{(1,16)}=23.6, p<0.0002\right)$. The linearity was low, regardless of whether or not the arena rotated $\left(0.25 \pm 0.01 ; F_{(1,16)}=0.39 ; p>\right.$ $0.84)$. The effect of day was not significant $\left(\mathrm{E}: F_{(3,48)}=0.94, p>\right.$ $0.43 ; T_{\text {max }}: F_{(3,48)}=0.21, p>0.89$; Lin: $\left.F_{(3,48)}=0.87, p>0.46\right)$ and neither were the interactions $\left(\mathrm{E}: F_{(3,48)}=2.01, p>0.13\right.$; $\left.T_{\text {max }}: F_{(3,48)}=0.56, p>0.69\right)$, except for the day by linearity interaction $\left(F_{(3,48)}=4.08 ; p>0.01\right)$. Linearity was greater during rotation, but it decreased across days, whereas it increased across the stable sessions (rotation day $1=$ stable day $4>$ all other sessions).

\section{Experiment 3b: does the TTX injection impair \\ Room + avoidance?}

The previous training ensured that the rats had learned the avoidance procedure, had habituated to the shallow water, and were performing Room + avoidance optimally before the effect of the TTX injection was tested. Injecting saline or TTX into one hippocampus did not reliably disrupt optimal Room + avoidance while the arena was rotating (Fig. 3C). There was a nonsignificant tendency for avoidance to be worse after the TTX injections. There was no effect of day $\left(\mathrm{E}: F_{(3,24)}=2.17, p>0.12 ; T_{\max }: F_{(3,24)}\right.$ $=2.66, p>0.07$; Lin: $\left.F_{(3,24)}=1.14, p>0.35\right)$.

\section{Discussion}

Unilateral TTX injection blocked spontaneous action and local field potentials (Olifer et al., 2004) and responses to perforant path stimulation (Klement et al., 2005), reducing commissural excitation of the uninjected hippocampus (Buzsaki and Czeh, 1981). The injection abolished place avoidance specifically when room and arena stimuli were continuously dissociated. Avoidance was spared when room and arena stimuli were organized by maintaining their mutual stability in (Room\&Arena) + training (Fig. $2 A$ ), by hiding room stimuli with darkness in Arena + train- 


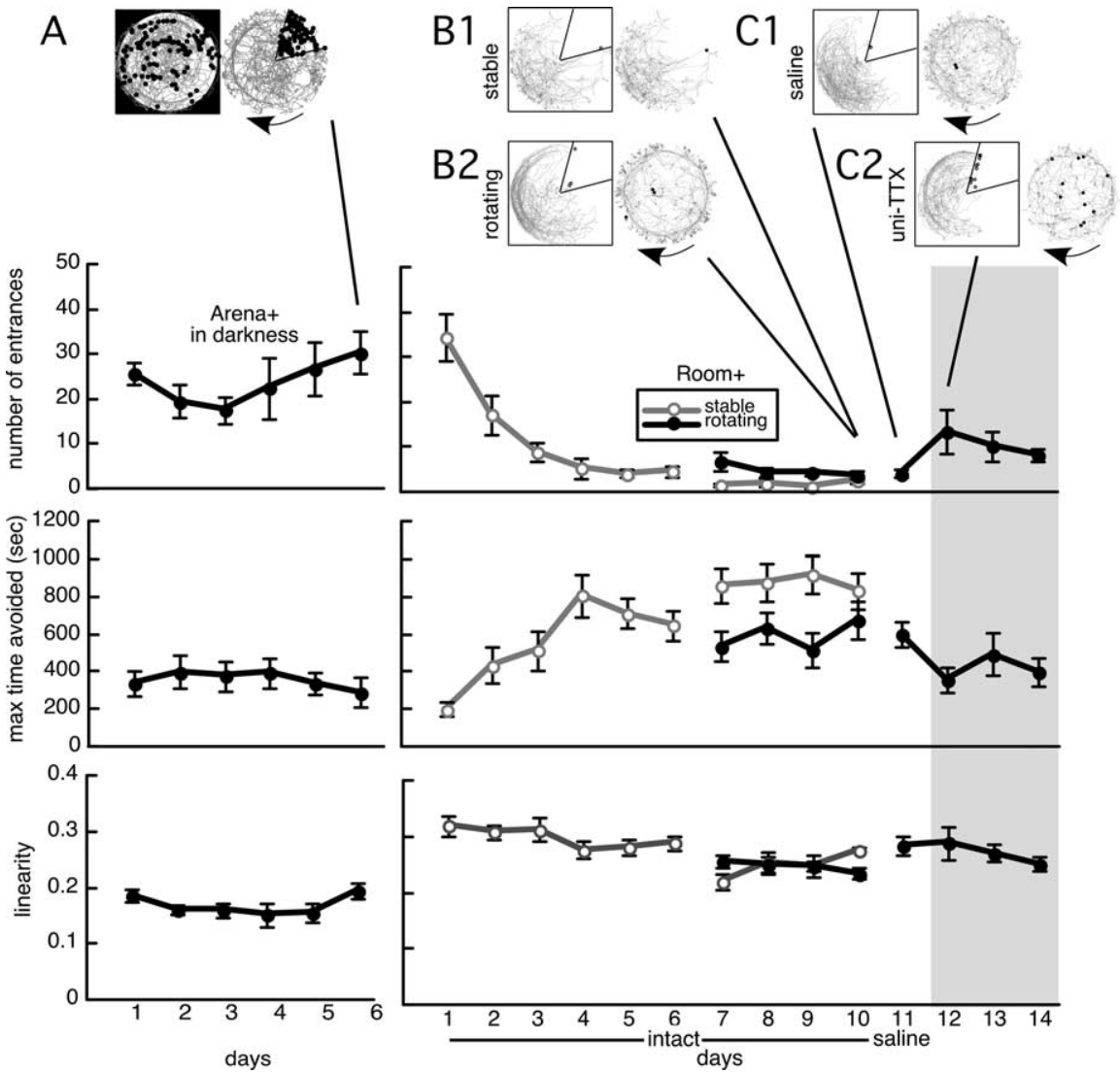

Figure 3. A, Experiment 2. Shallow water prevented Arena + place avoidance, because the salient arena cues were hidden. Entrances were high and the maximum time of avoidance was moderate, and neither improved. Linearity was low, indicating that the rat tended not to move in a directed manner. B1, Experiment 3a, Room + avoidance was acquired on the stable wet arena (B2) and was worse when the arena rotated. Entrances decreased, and the maximum time avoided increased to asymptotic levels. The linearity was high. Experiment 3b, Saline (C1) (day 11) or TTX (C2) (days 12-14; shaded) was injected into one hippocampus (uni-TTX). Neither injection reliably impaired Room + place avoidance, because none of the measures were reliably changed. The TTX may have initially disturbed Room + place avoidance, but the effect was not statistically significant. Tracks of a representative rat are shown from the day indicated by the line between the track and the graph. Tracks from the same rat are shown in $\boldsymbol{B}$ and $\boldsymbol{C}$. The absence of arena stimuli is represented by the absence of a circle in the arena frame representation of the track. Other figure elements are the same as in Figure 2.

ing (Fig. $2 B$ ), or by hiding arena stimuli with water in Room + training (Fig. 3C). A TTX-induced change of motivation, sensitivity to shock, or the motor ability to avoid cannot explain the selective impairment. Impaired Room + avoidance might have been expected, because continuous rotation dissociates selfmovement and room stimuli. Rats, however, learn not to use irrelevant self-motion cues for place avoidance (Stuchlik et al., 2001).

\section{Does impaired memory account for the pattern of place-avoidance deficits?}

Hypotheses that the hippocampus stores spatial, relational, and representational memories predict deficits after hippocampal dysfunction if the rat must learn or recall associations between shock and the stimuli that define a place. Bilateral TTX injections impaired retention of (Room\&Arena) + (Ježek et al., 2003) and Room + Arena - (Cimadevilla et al., 2000a) avoidance. Memory for room locations and shock-location associations was required after unilateral TTX injection in the (Room\&Arena) + , Room + , and Room + Arena - tasks. Because only Room + Arena - avoidance was impaired, the injection spared acquiring and recalling the relevant memory, suggesting the Room + Arena - task taxed another hippocampal function. Room+Arena- avoidance memory was abolished despite restricting posttraining unilateral inactivations to between-session intervals (Cimadevilla et al., 2001). It seems that the hippocampus has a role in memory not captured by the concepts of spatial, relational, or representational memory. Extrahippocampal memory systems were likely engaged in place avoidance at least during Arena+ avoidance (Fenton et al., 2002). Perhaps the hippocampus coordinates activity in these different systems (see the section on cognitive coordination below). Nonetheless, a frank memory impairment does not explain the data.

Does impaired navigation account for the pattern of place-avoidance deficits? Animal cognition and the role of hippocampus is routinely studied using water-maze tasks requiring a spatial representation of the subject's location and reinforcement. Hippocampal place cells (O'Keefe and Dostrovsky, 1971) were recorded in a variant of the water maze, suggesting that rats represent water-maze environments (Hollup et al., 2001; Brun et al., 2002). Place avoidance also requires representing the environment, current location, and the location of reinforcement. Place cells were recorded on stable and rotating arenas (Zinyuk et al., 2000) and while the rat performed (Room\&Arena)+ and Room + Arena + avoidance (Kelemen et al., 2004), suggesting that the placeavoidance environment is represented in hippocampal discharge. Unilateral TTX injection spared learning in the water maze (Fenton and Bureš, 1993, 1994; Fenton et al., 1995) but impaired retrieval (Kubik et al., 2004), replicating the effect of permanent partial lesions (Moser and Moser, 1998). Can a navigational deficit account for the selective impairment of Room+Arenaavoidance?

Navigational demand was similar in the Room + and Room + Arena - tasks, but only the latter was impaired. The (Room\&Arena)+, Room +, and Room+Arena- tasks all required representing room locations, but only Room+Arenaavoidance was impaired. Navigation during place avoidance need not be as accurate as in water-maze escape tasks, which require finding a relatively small location in a relatively large open field. A navigational impairment does not account for the data.

\section{Does impaired behavioral inhibition account for the pattern} of place-avoidance deficits?

The simplest formulation of the behavioral inhibition hypothesis is that the hippocampus is important when learned responses must be inhibited. Because foraging-based avoidance required inhibiting foraging, the hypothesis predicts a general TTXinduced impairment, but only the Room + Arena - task was impaired. The hypothesis fails to explain impaired Room + Arenaavoidance when there was no foraging and no previous training to avoid arena locations (Cimadevilla et al., 2001). 
A more complex formulation of the inhibition hypothesis is that the hippocampus is important when the subject must select from between conflicting responses, whether innate or learned. The TTX injection may have impaired the appropriate selection of whether to remain still or move in response to shock. This does not account for the spared Room + avoidance, which had the same conflict. Nor does it account for why rats impaired by TTX tended not to orient their escape from the to-be-avoided area once they received a shock and decided to move. The TTXinjected rats had less linear paths, suggesting that they inhibited their movements. This was not attributable to only the TTX injection, because the linearity was also lower when the rats were not impaired and arena stimuli were useful for the avoidance. Perhaps the TTX-injected rats used a different avoidance strategy when arena cues were useful. TTX injection did not change linearity in the Room + task, and although linearity was initially lower than in control rats during the Room + Arena - task, the linearity in the control rats eventually decreased to the level of the injected rats. Impaired behavioral inhibition does not account for the place-avoidance data.

\section{Does impaired cognitive coordination account for the pattern of place-avoidance deficits?}

Water-maze tasks were used to characterize hippocampusdependent spatial cognition in rats. Place-avoidance tasks make similar cognitive demands. In the presence of dissociated room and arena cues, place avoidance was organized according to the room cues alone in Room + Arena - avoidance and according to both room and arena cues in Room + Arena + avoidance (Fenton et al., 1998), indicating that the rat could segregate room and arena stimuli and satisfying criterion $\mathrm{ccl}$ for inferring cognitive coordination. Intact rats expressed Room + Arena - avoidance and even Room+Arena+ avoidance (Fenton et al., 1998) in which the use of arena stimuli for identifying the room to-beavoided place would be interfering, thus satisfying criterion cc2. Rats trained in (Room\&Arena) + avoidance expressed separate room and arena place-avoidance memories during extinction conditions (Bureš et al., 1998; Fenton et al., 1998). The room and arena memories represent potentially conflicting information, and thus dynamic contextual control of behavior was needed. The presence of concurrent stimulus conflict distinguishes the Room + Arena - and Room + Arena + tasks from traditional conditional association and contextual retrieval tasks. We conclude that avoidance behavior in these tasks depended on contextdependent, perceptual grouping and thus cognitive coordination can be inferred from normal place-avoidance behavior.

Control rats met the criteria for cognitive coordination in the familiar steady-state conditions in which TTX injection abolished Room + Arena - place avoidance (Fig. 2C), satisfying criterion $\mathrm{cd} 1$ for inferring impaired cognitive coordination. Escapes were poorly organized during the Room + Arena - task, suggesting that the TTX-injected rats did not appreciate the spatial localization of shock. The TTX injection spared (Room\&Arena)+, Arena + , and Room + avoidance (Figs. $2 A, B, 3 C$ ), conditions when room and arena stimuli were not dissociated, thus satisfying criterion $\mathrm{cd} 2$. The effect of the TTX injection satisfied the criteria for inferring impaired cognitive coordination.

Although Room + Arena- avoidance is learned within 10 min, task difficulty can explain the TTX-induced impairment. Task difficulty is a useful consideration when one can specify why the task was difficult. We suggest that the demand for cognitive coordination in Room + Arena - avoidance made it sensitive to the TTX injection.
The unilateral TTX injection may have impaired the contextual modulation or selective activation of place and shock memories that was necessary in the Room + Arena- task. Perhaps the hippocampus has a critical role in flexible or relational memory tasks (Shapiro and Eichenbaum, 1999), because it has a fundamental role in coordinating the activation of memories or the activity between memory systems. It may be advantageous to use this coordination perspective for studies of hippocampus and to use the theoretical framework from the literature on cognitive coordination. Formal and information theoretic methods have already been used to analyze neural discharge in terms of dynamic grouping, the neural process thought to underlie contextual modulation and perceptual grouping (Tononi et al., 1994; Phillips et al., 1995; Kay et al., 1998; Phillips and Craven, 2000; Sporns et al., 2000, Olypher et al., 2002).

Representing that room stimuli defined the Room + Arenato-be-avoided place, and arena stimuli were irrelevant, implies there are segregating and coordinating cognitive processes in rat. The coordination hypothesis ultimately depends on observing the explicit coordination of room- and/or arena-defined neural representations as may be evident in simultaneous hippocampal place cell representations of both room and arena locations. Place cell discharge represented both room and arena locations when room and arena stimuli were put into conflict. Some cells discharged relative to room stimuli, some discharged relative to arena stimuli, and the discharge of some was controlled by both room and arena stimuli (Gothard et al., 1996; Tanila et al., 1997a,b,c; Brown and Skaggs, 2002; Knierim, 2002; Lee et al., 2004; Rivard et al., 2004). This pattern of response was also observed on the continuously rotating arena (Zinyuk et al., 2000) and during Room + Arena+ place avoidance (Kelemen et al., 2004). Navigation training on the rotating arena even increased the expression of place cell firing fields during continuous rotation (Zinyuk et al., 2000) and place avoidance (Kelemen et al., 2004).

Impaired cognitive coordination may underlie dissociated schizophrenia (Phillips and Silverstein, 2003), making parallels between the behavior of schizophrenics and the TTX-injected rats noteworthy. TTX injection did not impair (Room\&Arena)+ avoidance or water-maze learning (Fenton et al., 1993; Kubik et al., 2004), analogous to reports that patients do not manifest cognitive coordination deficits when stimuli have strong prepotent organization. The TTX injection improved Arena+ avoidance, analogous to reports that schizophrenics identify stimuli better than controls when the gestalt processes of controls are activated (Place and Gilmore, 1980; Silverstein et al., 1996).

\section{References}

Brown JE, Skaggs WE (2002) Concordant and discordant coding of spatial location in populations of hippocampal CA1 pyramidal cells. J Neurophysiol 88:1605-1613.

Brun VH, Otnass MK, Molden S, Steffenach HA, Witter MP, Moser MB, Moser EI (2002) Place cells and place recognition maintained by direct entorhinal-hippocampal circuitry. Science 296:2243-2246.

Bureš J, Fenton AA, Kaminsky Y, Rossier J, Sacchetti B, Zinyuk L (1997) Dissociation of exteroceptive and idiothetic orientation cues: effect on hippocampal place cells and place navigation. Philos Trans R Soc Lond B Biol Sci 352:1515-1524.

Bureš J, Fenton AA, Kaminsky Y, Wesierska M, Zahalka A (1998) Rodent navigation after dissociation of the allocentric and idiothetic representations of space. Neuropharmacology 37:689-699.

Buzsaki G, Czeh G (1981) Commissural and perforant path interactions in the rat hippocampus. Field potentials and unitary activity. Exp Brain Res 43:429-438.

Chan KH, Morell JR, Jarrard LE, Davidson TL (2001) Reconsideration of 
the role of the hippocampus in learned inhibition. Behav Brain Res 119:111-131.

Cimadevilla JM, Fenton AA, Bureš J (2000a) Functional inactivation of dorsal hippocampus impairs active place avoidance in rats. Neurosci Lett 285:53-56.

Cimadevilla JM, Kaminsky Y, Fenton AA, Bureš J (2000b) Passive and active avoidance as a tool of spatial memory research in rats. J Neurosci Methods 102:155-164.

Cimadevilla JM, Wesierska M, Fenton AA, Bureš J (2001) Inactivating one hippocampus impairs avoidance of a stable room-defined place during dissociation of arena cues from room cues by rotation of the arena. Proc Natl Acad Sci USA 98:3531-3536.

Eichenbaum H, Dudchenko P, Wood E, Shapiro M, Tanila H (1999) The hippocampus, memory, and place cells: is it spatial memory or a memory space? Neuron 23:209-226.

Fenton AA, Bureš J (1993) Place navigation in rats with unilateral tetrodotoxin inactivation of the dorsal hippocampus: place but not procedural learning can be lateralized to one hippocampus. Behav Neurosci 107:552-564.

Fenton AA, Bureš J (1994) Interhippocampal transfer of place navigation monocularly acquired by rats during unilateral functional ablation of the dorsal hippocampus and visual cortex with lidocaine. Neuroscience 58:481-491.

Fenton AA, Arolfo MP, Nerad L, Bureš J (1995) Interhippocampal synthesis of lateralized place navigation engrams. Hippocampus 5:16-24.

Fenton AA, Wesierska M, Kaminsky Yu, Bureš J (1998) Both here and there: simultaneous expression of autonomous spatial memories in rats. Proc Natl Acad Sci USA 95:11493-11498.

Fenton AA, Bureš J, Cimadevilla JM, Olypher AV, Wesierska M, Zinyuk L (2002) Place cell activity during overtly purposeful behavior (in dissociated reference frames). In: The neural basis of navigation: evidence from single cell recording (Sharp PE, ed), pp 59-80. Boston: Kluwer Academic.

Gothard KM, Skaggs WE, Moore KM, McNaughton BL (1996) Binding of hippocampal CA1 neural activity to multiple reference frames in a landmark-based navigation task. J Neurosci 16:823-835.

Hollup SA, Molden S, Donnett JG, Moser MB, Moser EI (2001) Place fields of rat hippocampal pyramidal cells and spatial learning in the water maze. Eur J Neurosci 13:1197-1208.

Jarrard LE (1973) The hippocampus and motivation. Psychol Bull 79:1-12.

Ježek K, Wesierska M, Fenton AA (2003) Hippocampus-dependent retrieval and hippocampus-independent extinction of place avoidance navigation, and stress-induced out-of-context activation of a memory revealed by reversible lesion experiments in rats. Physiol Res 51 [Suppl 1]:S35-S47.

Kay J, Floreano D, Phillips WA (1998) Contextually guided unsupervised learning using local multivariate binary processors. Neural Netw 11:117-140.

Kelemen E, Klement D, Olypher AV, Fenton AA (2004) The continuous rotation of local cues relative to distal cues is reflected in the discharge of hippocampal cells. Soc Neurosci Abstr 34:667.5.

Klement D, Paštálková E, Fenton AA (2005) Tetrodotoxin infusions into the dorsal hippocampus block non-locomotory place recognition. Hippocampus, in press.

Knierim JJ (2002) Dynamic interactions between local surface cues, distal landmarks, and intrinsic circuitry in hippocampal place cells. J Neurosci 22:6254-6264.

Kubik S, Cimadevilla JM, Miranda R, López L, Arias JL, Fenton AA (2004) Dissociation of hippocampal function: injecting tetrodotoxin into one hippocampus impairs learning and spares retrieval of place avoidance but spares learning and impairs retrieval of water maze escape location. FENS Abstr 2:A149.9.

Lee I, Yoganarasimha D, Rao G, Knierim JJ (2004) Comparison of population coherence of place cells in hippocampal subfields CA1 and CA3. Nature 430:456-459.

McNaughton N (1997) Cognitive dysfunction resulting from hippocampal hyperactivity-a possible cause of anxiety disorder? Pharmacol Biochem Behav 56:603-611.
Moser M-B, Moser EI (1998) Distributed encoding and retrieval of spatial memory in the hippocampus. J Neurosci 18:7535-7542.

O'Keefe J, Dostrovsky J (1971) The hippocampus as a spatial map. Preliminary evidence from unit activity in the freely-moving rat. Brain Res 34:171-175.

O'Keefe J, Nadel L (1978) Hippocampus as a cognitive map. Oxford: Clarendon.

Olifer AV, Wesierska M, Klement D, Dockery C, Fenton AA (2004) An experimental and computational model of cognitive disorganization in the rat. FENS Abstr 2:A182.3.

Olton DS, Walker JA, Wolf WA (1982) A disconnection analysis of hippocampal function. Brain Res 233:241-253.

Olypher AV, Lansky P, Fenton AA (2002) Properties of the extra-positional signal in hippocampal place cell discharge derived from the overdispersion in location-specific firing. Neuroscience 111:553-656.

Paxinos G, Watson M (1989) The rat brain in stereotaxic coordinates, Ed 2. San Diego: Academic.

Phillips WA, Craven B (2000) Interactions between coincident and orthogonal cues to texture boundaries. Percept Psychophys 62:1019-1038.

Phillips WA, Silverstein SM (2003) Convergence of biological and psychological perspectives on cognitive coordination in schizophrenia. Behav Brain Sci 26:65-82, 82-137.

Phillips WA, Singer W (1997) In search of common foundations for cortical computation. Behav Brain Sci 20:657-683, 683-722.

Phillips WA, Kay J, Smyth D (1995) The discovery of structure by multistream networks of local processors with contextual guidance. Network $6: 1-22$.

Place EJS, Gilmore GC (1980) Perceptual organization in schizophrenia. J Abnorm Psych 89:409-418.

Rivard B, LiY, Lenck-Santini PP, Poucet B, Muller RU (2004) Representation of objects in space by two classes of hippocampal pyramidal cells. J Gen Physiol 124:9-25.

Shapiro ML, Eichenbaum H (1999) Hippocampus as a memory map: synaptic plasticity and memory encoding by hippocampal neurons. Hippocampus 9:365-384.

Silverstein SM, Knight RA, Schwarzkopf SB, West LL, Osborn LM, Kamin D (1996) Stimulus configuration and context effects in perceptual organization in schizophrenia. J Abnorm Psychol 105:410-420.

Sporns O, Tononi G, Edelman GM (2000) Connectivity and complexity: the relationship between neuroanatomy and brain dynamics. Neural Netw 13:909-922.

Stuchlik A, Fenton AA, Bureš J (2001) Substratal idiothetic navigation of rats is impaired by removal or devaluation of extramaze and intramaze cues. Proc Natl Acad Sci USA 98:3537-3542.

Sutherland RJ, Whishaw IQ, Kolb BA (1983) Behavioural analysis of spatial localization following electrolytic, kainite- or colchicine-induced damage to the hippocampal formation in the rat. Behav Brain Res 7:133-153.

Tanila H, Shapiro ML, Eichenbaum H (1997a) Discordance of spatial representation in ensembles of hippocampal place cells. Hippocampus 7:613-623

Tanila H, Shapiro M, Gallagher M, Eichenbaum H (1997b) Brain aging: changes in the nature of information coding by the hippocampus. J Neurosci 17:5155-5166.

Tanila H, Sipila P, Shapiro M, Eichenbaum H (1997c) Brain aging: impaired coding of novel environmental cues. J Neurosci 17:5167-5174.

Tononi G, Sporns O, Edelman GM (1994) A measure for brain complexity: relating functional segregation and integration in the nervous system. Proc Natl Acad Sci USA 91:5033-5037.

Tracy AL, Jarrard LE, Davidson TL (2001) The hippocampus and motivation revisited: appetite and activity. Behav Brain Res 127:13-23.

Zhuravin IA, Bureš J (1991) Extent of the tetrodotoxin induced blockade examined by pupillary paralysis elicited by intracerebral injection of the drug. Exp Brain Res 83:687-690.

Zinyuk L, Kubik S, Kaminsky Yu, Fenton AA, Bureš J (2000) Understanding hippocampal activity by using purposeful behavior: place navigation induces place cell discharge in both task-relevant and task-irrelevant spatial reference frames. Proc Natl Acad Sci USA 97:3771-3776. 